Original Article

\title{
EFFECT OF BOILING AND MICROWAVE ASSISTED PROCESSING ON THE ANTIMICROBIAL EFFICACY OF VITAMIN-C IN EMBLICA OFFICINALIS
}

\author{
PAYEL SUTRADHAR ${ }^{*}$, SHALINI GHOSH², BINITA KUMARI ROY ${ }^{3}$
}

\author{
1,2,3 Department of Microbiology, Institute of Genetic Engineering. Kolkata, West Bengal, India \\ Email: payel.sutradhar@gmail.com
}

Received: 13 Jun 2020, Revised and Accepted: 16 Aug 2020

\begin{abstract}
Objective: The present work aimed to expand the awareness of restoring vitamin-C in its active form on different heat exposures. The effect of microwave-assisted processing and boiling of the aqueous crude extract of citrus fruit Emblica officinalis (amla) has been correlated with its antimicrobial efficacy against E. coli.

Methods: The aqueous crude extract of dried amla pulp exposed to microwave radiation(600W,5 min) and boiling (5 min) were titrimetrically estimated for vitamin-C content by DCPIP-(2,6, Dinitrophenol indophenol) method and compared the same with the untreated sample. These three samples were studied for their effect on the growth pattern of $E$. coli turbidimetrically. The antimicrobial susceptibility test by agar cup well diffusion method was further followed to measure the zone of inhibitions (ZOI) for these three test extracts against E. coli.

Results: The total estimated vitamin-C content was $26.76 \mathrm{mg} / 100 \mathrm{~g}, 25.35 \mathrm{mg} / 100 \mathrm{~g}$ and $21.12 \mathrm{mg} / 100 \mathrm{~g}$ in the untreated extract (UTE), microwaved extract (MWE) and boiled extract (BE) respectively. At a higher concentration $(0.8 \mathrm{mg} / \mathrm{ml})$, the UTE showed a greater ZOI of $20 \mathrm{~mm}$ and a comparable ZOI of $18 \mathrm{~mm}$ for the MWE against E. coli. In addition, a reduced ZOI of $10 \mathrm{~mm}$ was recorded in case of the BE. At a lowest concentration $(0.05 \mathrm{mg} / \mathrm{ml})$, the UTE inhibited the growth with a least ZOI of $7 \mathrm{~mm}$, whereas no inhibition zones were detected for MWE and BE at this concentration.

Conclusion: The present investigation demonstrated the effect of boiling and microwave-assisted processing on the content of bioactive vitamin-C and its antimicrobial activity. The DCPIP method calculated a more vitamin-C retention in the MWE than the BE. As the boiling method destroyed the vitamin more rapidly, a higher growth rate of $E$. coli was measured in the presence of BE than the UTE and MWE. In addition, the antimicrobial assay also showed a least inhibitory effect against $E$. coli in the presence of the BE. A moderate inhibitory effect for MWE was also detected. Thus the present investigation proved that the boiling process destroys vitamin-C present in a food sample to a higher extent than the microwave-assisted processing.
\end{abstract}

Keywords: Vitamin C, DCPIP, Emblica officinalis (amla), Antimicrobial efficacy, E. coli, Zone of inhibition, Microwave, Boiling

(c) 2020 The Authors. Published by Innovare Academic Sciences Pvt Ltd. This is an open access article under the CC BY license (http://creativecommons.org/licenses/by/4.0/) DOI: http://dx.doi.org/10.22159/ijcpr.2020v12i5.39780. Journal homepage: https://innovareacademics.in/journals/index.php/ijcpr

\section{INTRODUCTION}

Vitamin-C or ascorbic acid present in many citrus fruits is an essential temperature-sensitive water-soluble vitamin and known to be a potent antimicrobial and antioxidant agent. The miraculous fruits of Emblica officinalis called Indian gooseberry (amla) are the natural source of vitamin-C with other myriad bioactive compounds valuable in medicinal point of view. The plants are occasionally found in tropical and subtropical regions of India offering a power house of nutrients. Antibacterial activity of different extracts of this fruit were evaluated against $E$. coli as studied and reported [1]. The medicinal plants are a treasure to be exploited for therapeutic aids. The use of natural products increased the demands for effective and safer therapeutics as compared to synthetic drugs or antibiotics. The excessive use of antibiotics, resulting in the emergence of resistant microbial strain brings an option for natural products as alternative medical therapy [2]. Ascorbic acid known as vitamin-C is present in Gooseberry, Amla, Bitter gourd etc. in high amounts. Generally it is present in all fresh vegetables and fruits. It is a water-soluble and heat labile vitamin. The antioxidant property of this vitamin also inhibits the $H$. pylori by scavenging free radicals and thus can be effective against gastric carcinoma. Application of microwave radiation for heating the natural products and their extractions are being advantageous for shorter extraction time, higher extraction rate and lower cost, over other traditional method like boiling in water [3, 4]. As the heat labile vitamin is an effective antimicrobial agent, the cooking methods involving different modes of heat processing might cause degradation or loss of this valuable nutrient.

The current work demonstrated the effect on the antimicrobial potency of the vitamin-C present in the crude aqueous extract of dried Emblica officinalis fruit pulps after heat treatments. The amount of vitamin-C was effectively estimated by DCPIP method by volumetric titration, which is an easy, rapid and a large number of samples can be analysed in a short time. The study also highlighted the strategy for a good cooking method of vitamin C rich foods without loosing the valuable property of this active bio compound.

\section{MATERIALS AND METHODS}

\section{Collection and preparation of the extract}

The fresh Emblica officinalis fruit were procured from the local registered vegetable shop of the Dum Dum area of Kolkata, West Bengal (India). They were cleaned, cut into small pieces and shadedried covered with blotting papers for $8 \mathrm{~d}$. The dried pulp was ground to a fine powder and stored in a closed amber coloured bottle for further analysis.10 g of the sample was soaked in $100 \mathrm{ml}$ of autoclaved distilled water and filtered to prepare a fresh working sample of the extract.

\section{Chemical estimation of vitamin-C}

The freshly prepared extract were subjected to boiling ( $5 \mathrm{~min}$ ) and microwave radiation ( $5 \mathrm{~min}$ at $600 \mathrm{~W}$ ) separately, marked as $\mathrm{BE}$ and MWE, respectively. The UTE (untreated extract) was also prepared for reference. All the three sample extracts were chemically assayed for vitamin-C by DCPIP method [5]. $5 \mathrm{ml}$ of the working standard solution pipetted into $100 \mathrm{ml}$ of conical flask and $10 \mathrm{ml}$ of $4 \%$ oxalic acid was added, then titrated against the dye $\left(\mathrm{V}_{1} \mathrm{ml}\right)$. An appearance of pink colour which persists for a few minutes was the endpoint. The amount of the dye consumed is equivalent to the amount of ascorbic acid. $5 \mathrm{ml}$ of sample were added to $10 \mathrm{ml}$ of $4 \%$ oxalic acid 
and titrated against the dye $\left(\mathrm{V}_{2} \mathrm{ml}\right) . \mathrm{V}_{2}$ was determined for each of the three samples separately.

The estimation of vitamin-C content was calculated by the formula [5]

Ascorbic acid ${ }_{(\mathrm{mg} / 100 \mathrm{~g} \text { sample })}=\left(0.5 / \mathrm{V}_{1} \mathrm{ml}\right) \times\left(\mathrm{V}_{2} / 5 \mathrm{ml}\right) \times(100 \mathrm{ml} /$ wt. of the sample) $\times 100$

\section{Isolation and inoculum preparation}

The test culture of E. coli $(20 \mu \mathrm{l})$ provided by the Microbiology department of the Institute of Genetic Engineering was subcultured in $60 \mathrm{ml}$ of Luria Broth. The culture was incubated for $18 \mathrm{~h}$ at 35-37 ${ }^{\circ} \mathrm{C}$. This culture was studied by basic microbiological and biochemical tests [6].

\section{Heat treatments of crude extract and study of growth pattern}

$8 \mathrm{mg}$ of amla powder was taken in three separate sterile $50 \mathrm{ml}$ Erlenmeyer flask and $10 \mathrm{ml}$ autoclaved distilled water was added in each flask. After $5 \mathrm{~min}$, the three suspensions were separately sterilized by syringe filter $(0.22 \mu \mathrm{m}$ pore size $)$ and transferred to another three sets of $50 \mathrm{ml}$ sterile Erlenmeyer flask. The first set was left untreated, the second set was boiled for $5 \mathrm{~min}$ and the third set was microwaved for $5 \mathrm{~min}$ at $600 \mathrm{~W}$. Each of these three sample extracts were separately supplemented to $60 \mathrm{ml}$ sterile Luria broth, inoculated with $20 \mu \mathrm{l}$ of $E$. coli test culture and incubated at $35-37^{\circ} \mathrm{C}$. A control was taken by inoculating test culture in Luria broth without supplementing with amla powder extract. All the four samples were studied for the growth pattern of $E$. coli in further steps. Aseptic conditions were followed strictly.

\section{Turbidimetric study of bacterial growth pattern}

A turbidimetric assay was followed for the quantification of viable bacterial densities. The turbidity of the culture or bacterial cell density was measured by photo colorimeter (ESICO-MODEL 1311) at $620 \mathrm{~nm}$ in short intervals and OD was recorded. OD vs time (min) graph was plotted to show the growth pattern in presence of untreated, treated (boiled/microwaved) and in the absence of the extract [7]. Aseptic conditions were followed strictly.

\section{Antimicrobial assay}

The three sample extracts; BE, MWE and UTE were studied for antimicrobial assay against test culture $E$. coli by agar cup well diffusion method. Different working concentrations of $0.05,0.2,0.4$ and $0.8 \mathrm{mg} / \mathrm{ml}$ were prepared for each samples. Nutrient agar plates were seeded uniformly with $20 \mu \mathrm{l}$ of $18 \mathrm{~h}$ grown test cultures of $E$. coli. Wells were bored over these agar plates in proper spacing with the help of a sterile cork borer. The wells were filled with $100 \mu \mathrm{l}$ of the above-mentioned test aqueous extract separately with different working concentrations. The plates were incubated for $24 \mathrm{~h}$ at 35-37 ${ }^{\circ} \mathrm{C}$ and studied for the zone of inhibitions. Less than $5 \mathrm{~mm}$ zone of inhibition was considered as negligible.

\section{RESULTS}

\section{DCPIP assay of vitamin-C (ascorbic acid)}

The volumetric titrations by DCPIP method recorded the vitamin-C content as $26.76,25.85$ and $21.12 \mathrm{mg} / 100 \mathrm{~g}$ in case of the UTE, MWE and BE test samples, respectively [fig. 1]. The UTE contains the highest amount of active vitamin-C, whereas the boiled extract contains the least. The microwaved sample extract measured a comparable content of this active vitamin similar to that of the untreated sample. This result showed that the boiling method destroyed the vitamin-C more effectively than microwaved processing. A significant amount of this vitamin has been retained when the sample was not thermally processed (untreated).
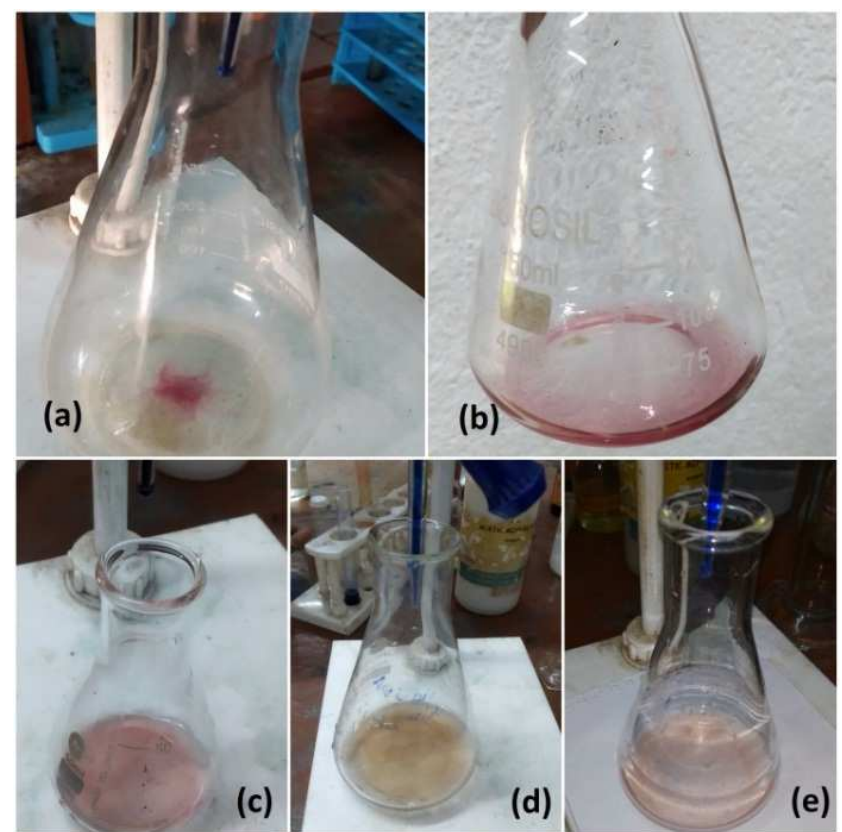

Fig. 1: Volumetric titrations(a) Ascorbic acid blank titrated against the dye(DCPIP);(b)End point (ascorbic acid blank);(c)End point(titration of untreated extract); (d)End point(titration of boiled extract);(e) End point(titration of microwaved extract)

\section{Effect on bacterial growth pattern}

The titrimetric study proved that the amount and activity of vitaminC greatly varies for three different samples (UTE, MWE and BE). The graphical representation highlighted the fact that the vitamin-C present in these test extracts greatly effected the growth rate of $E$. coli [fig. 2]. The growth rate in the presence of boiled extract (BE) is comparable with that of the growth rate in the absence of the extract. As the vitamin-C degrades at high temperatures [8] after boiling the extract and thus the bacterial growth pattern was quite similar to that in absence of the extract. Also the growth rate in the presence of the microwaved (MWE) extract is comparable with that of the growth rate in the presence of untreated extract (UTE) suggesting that the vitamin is in active form and effecting the growth negatively might be due to its antimicrobial property. The 
microwave-assisted processing could retain more amount of vitamin $\mathrm{C}$ which has been proved by chemical estimation as well. samples were further studied for antimicrobial susceptibility test by agar cup well diffusion method against the test bacteria $E$. coli.

Therefore As it is evidend that the vitamin-C is a potent antimicrobial nutrient, these heat-treated and untreated test

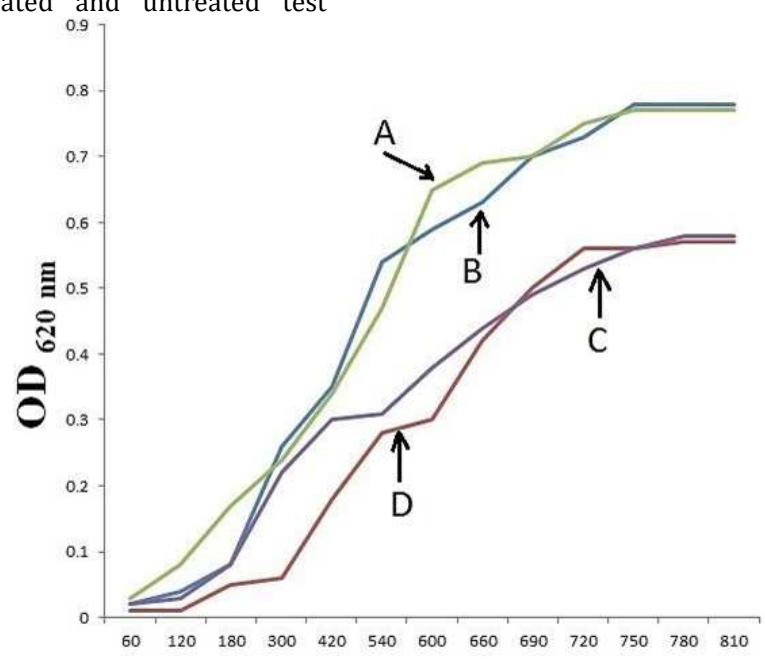

Time in min

Fig. 2: Graphical representation for the effect of the different test extracts on the $E$. coli growth rate.(A)Growth in the presence of boiled extract; (B)Growth in the absence of extract; (C)Growth in the presence of microwaved extract; (D)growth in the presence of untreated extract

\section{Antimicrobial susceptibility assay}

The UTE showed clear zone of inhibitions of 7,13,19, and $20 \mathrm{~mm}$ at a concentration of $0.05,0.2,0.4,0.8 \mathrm{mg} / \mathrm{ml}$ respectively. The $\mathrm{MWE}$ showed 12 and $18 \mathrm{~mm}$ at 0.4 and $0.8 \mathrm{mg} / \mathrm{ml}$, whereas no inhibition zones were detected at lower concentration of 0.05 and $0.2 \mathrm{mg} / \mathrm{ml}$ [table 1]. The antimicrobial effect is relatively comparable because microwave processing retained some amount of this vitamin in its active form. The sample processed by boiling showed $10 \mathrm{~mm}$ inhibition zone at a higher concentration of $0.8 \mathrm{mg} / \mathrm{ml}$ with no inhibition zones at lower concentrations [fig. 3]. This showed that the boiling method for BE destroys the vitamin and thus, detectable antimicrobial efficacy could be recorded at a higher concentration of BE. On the other hand, UTE showed a gradual increase in the inhibition zone with increasing concentrations as the vitamin is present in its active form. To increase the antimicrobial activity of hot/boiling water extracts, the time and temperature of the extraction process should also be carefully considered [9].

Table 1: Observation table for the clear zone of inhibitions

\begin{tabular}{|c|c|c|c|}
\hline \multirow[t]{2}{*}{ Concentrations (mg/ml) } & \multicolumn{3}{|c|}{ Zones of inhibitions (in $\mathrm{mm}$ ) of dried amla test extract $(100 \mu \mathrm{l})$} \\
\hline & Untreated sample (UTE) & Microwaved sample (MWE) & Boiled sample (BE) \\
\hline 0.05 & 7 & Not detected & Not detected \\
\hline 0.2 & 13 & Not detected & Not detected \\
\hline 0.4 & 19 & 12 & Not detected \\
\hline 0.8 & 20 & 18 & 10 \\
\hline
\end{tabular}




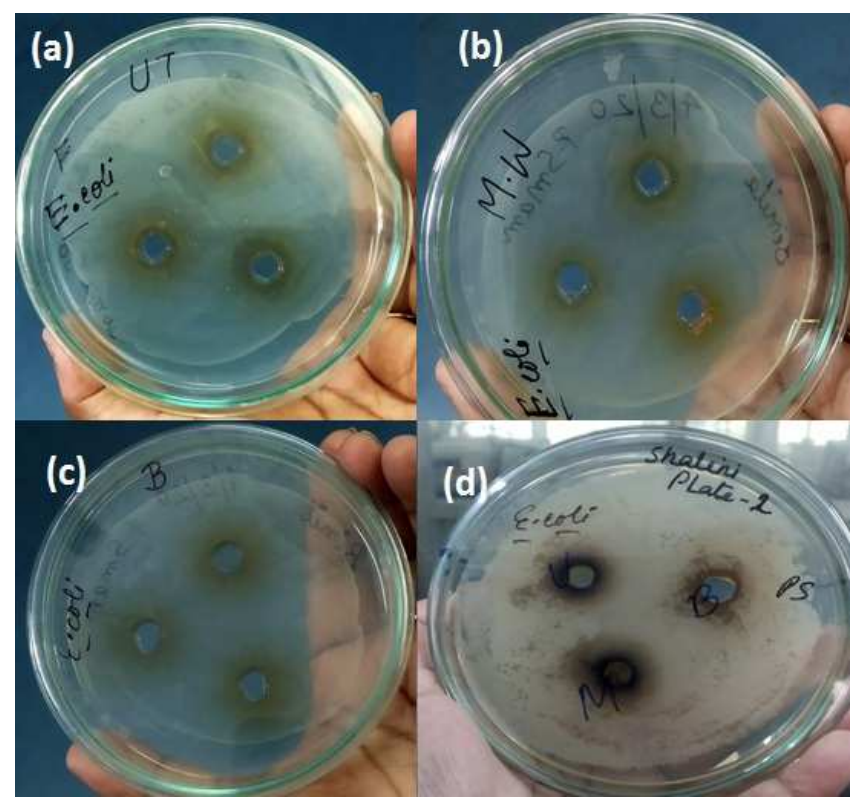

Fig. 3: Zone of inhibitions showed by agar well diffusion method. (a)Untreated extract(UTE); (B) Microwaved extract (MWE);(c)Boiled extract(BE);(d)UTE,MWE,BE at higher concentration

\section{DISCUSSION}

It was observed that the mode of heat processing is very important factor in retention or degradation of ascorbic acid or vitamin-C present in the dried amla pulp. The result showed that boiling or water blanching at higher temperatures for $5 \mathrm{~min}$ decreases the Vitamin-C content of the sample. The microwave assisted methods are always very advantageous for nutrient extraction [10]. The amount of Vitamin-C was also retained in microwaved assisted processing as compared to blanching or boiling. This present study justified that boiling destroys vitamin- $C$ and thus showed a minimum zone of inhibitions. Whereas the normal untreated amla aqueous extract with higher active vitamin-C content (chemically estimated by DCPIP method) showed a maximum zone of inhibition due to the potent antimicrobial activity of the Vitamin-C.

\section{CONCLUSION}

Vitamin-C is a potent antimicrobial agent. The present study focussed on the effect of Vitamin-C in the growth pattern of $E$. coli. The amount of vitamin-C estimated by DCPIP method was maximum in untreated (UTE)which was found comparable in microwaved (MWE) extract and minimum in boiled (BE) dried amla pulp extract. The antimicrobial efficacy of the test extracts against E. coli was found to be highest for UTE due to the presence of active vitamin; reduced remarkably for BE due to boiling of the extract; moderately reduced due to microwaveassisted processing of the amla extract. The work concluded that the decrease or degradation of bioactive vitamin- $C$ content in amla extract due to heat processing also decreases the zone of inhibitions and increases the growth rate of the bacteria (E. coli). The study also may emphasize on the fact that the antimicrobial effect of the vitamin-C decreases on increasing the temperature and also varies with different modes of heat processing. The present study was in agreement with the work reported by Rumm-Kreuter and Demmel [11]. This investigation could open new insights to develop novel scientific strategies for cooking to restore such water-soluble and temperaturesensitive nutrients present in the foods for maximum health benefits.

\section{ACKNOWLEDGEMENT}

The authors acknowledge the Director and Vice-Principal of the Institute of Genetic Engineering (IGE) for funding and affiliation. We are also thankful to other laboratory members of IGE for their enthusiastic participation in the present work.

\section{FUNDING}

Nil

\section{AUTHORS CONTRIBUTIONS}

All the authors have contributed equally.

\section{CONFLICTS OF INTERESTS}

The authors report no conflicts of interest in this work.

\section{REFERENCES}

1. Verghese RJ, Mathew SK, David A. Antimicrobial activity of vitamin C demonstrated on uropathogenic Escherichia coli and Klebsiella pneumoniae. J Curr Res Sci Med 2017;3:88-93.

2. Sudha K, Baskaran D, Dhanalakshmi B, Pugazhenthi TR. Determination of the antimicrobial activity of fruits. Int J Med Pharm Sci 2017;7:1-8.

3. Delazar A, Nahar L, Hamedeyazdan S, Sarker Sd. Microwaveassisted extraction in natural products isolation. Methods Mol Biol 2012;864:89-115.

4. Hui Min Zhang, Noriko Wakisaka MS, Osamu Maeda MS, Tatsuo Yamamoto. Vitamin $\mathrm{C}$ inhibits the growth of a bacterial risk factor for gastric carcinoma: Helicobacter pylori. Am Cancer Soc 2000;80:1897-903.

5. Sadashivam S, Theymoli Balasubramanian. In: Practical Manual in Biochemistry Tamil Nadu Agricultural University, Coimbatore; 1987.

6. Cappuccino James G, Sherman Natalie. In: Microbiology: A laboratory manual: $10^{\text {th }}$ edition. SUNY Rockland Community College; 2014.

7. Geller, Bruce, Deere, Jesse, Tilley. Antisense phosphorodiamidate morpholino oligomer inhibits viability of Escherichia coli in pure culture and in mouse peritonitis. J Antimicrobial Chemother 2005;55:983-8.

8. Igwemmar NC, Kolawole SA, Imran IA. Effect of heating on vitamin c content of some selected vegetables. Int J Sci Technol Res 2013;2:209-12.

9. Caputo L, Quintieri L, Cavalluzzi MM, Lentini G, Habtemariam S. Antimicrobial and antibiofilm activities of citrus water-extracts obtained by microwave-assisted and conventional methods. Biomedicines 2018;6:70.

10. Proestos Charalampos, Komaitis Michael. Application of microwave-assisted extraction to the fast extraction of plant phenolic compounds. Food Sci Technol 2008;41:652-9.

11. Rumm Kreuter D, Demmel I. Comparison of vitamin losses in vegetables due to various cooking methods.J Nutr Sci Vitaminol 1990;36 Suppl 1:S7-14, S14-5. 